\title{
Social Networks and Subjective Wellbeing in Australia: New Evidence from a National Survey
}

DOI:

$10.1177 / 0038038518760211$

\section{Document Version}

Accepted author manuscript

Link to publication record in Manchester Research Explorer

\section{Citation for published version (APA):}

Huang, X., Western, M., Bian, Y., Li, Y., Côté, R., \& Huang, H. (2018). Social Networks and Subjective Wellbeing in Australia: New Evidence from a National Survey. Sociology. https://doi.org/10.1177/0038038518760211

\section{Published in:}

Sociology

\section{Citing this paper}

Please note that where the full-text provided on Manchester Research Explorer is the Author Accepted Manuscript or Proof version this may differ from the final Published version. If citing, it is advised that you check and use the publisher's definitive version.

\section{General rights}

Copyright and moral rights for the publications made accessible in the Research Explorer are retained by the authors and/or other copyright owners and it is a condition of accessing publications that users recognise and abide by the legal requirements associated with these rights.

\section{Takedown policy}

If you believe that this document breaches copyright please refer to the University of Manchester's Takedown Procedures [http://man.ac.uk/04Y6Bo] or contact uml.scholarlycommunications@manchester.ac.uk providing relevant details, so we can investigate your claim.

\section{OPEN ACCESS}




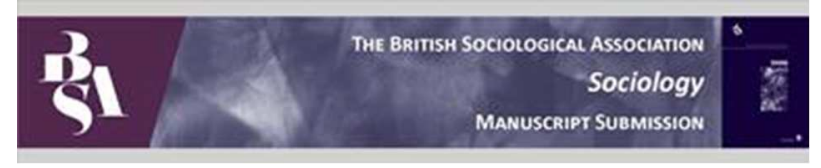

Social Networks and Subjective Wellbeing in Australia: New Evidence from a National Survey

\begin{tabular}{|r|l|}
\hline Journal: & Sociology \\
\hline Manuscript ID & SOC-May-2017-ARTC-210.R1 \\
\hline Manuscript Type: & Article \\
\hline Keywords: & $\begin{array}{l}\text { Australia, Happiness, Life satisfaction, Social networks, Subjective } \\
\text { wellbeing }\end{array}$ \\
\hline \multicolumn{2}{|l}{} \\
\hline
\end{tabular}

SCHOLARONE

Manuscripts 


\title{
Social Networks and Subjective Wellbeing in Australia: New Evidence from a National Survey
}

\begin{abstract}
:
The paper draws on data from a national survey in Australia in 2014 to examine how social networks affect life satisfaction and happiness. Findings show that social network composition, social attachment, perceived social support, and the volume of social resources are significantly positively associated with life satisfaction and happiness. Stress about social commitments, feeling restricted by social demands, and being excluded by a social group are negatively associated with life satisfaction and happiness. These results indicate that social networks have both 'bright side' and 'dark side' effects on subjective wellbeing.
\end{abstract}

Keywords: Australia, happiness, life satisfaction, social networks, subjective wellbeing

\section{Introduction}

Across the social sciences, social networks have been found to play an important role in educational attainment (Furstenberg and Hughes, 1995), parenting (Hagan et al., 1996), crime reduction (Hagan and McCarthy, 1995) and employment (Authors, 2009; Authors, 2011; Authors, 2015). In recent years, social scientists and policy makers have asserted that social networks also matter for health and wellbeing (Christakis and Fowler, 2009; Huxhold et al., 2013). However, despite the ubiquity of the social network concept scholars have highlighted a number of problems with theoretical and empirical work (Durlauf and Fafchamps, 2005; Lin, 2001; Lyons, 2011). In this paper we introduce a new model for the relationship of social networks to subjective wellbeing (SWB) and present data from a national Australian survey to explore the model.

Subjective wellbeing refers to people's evaluations of their own lives, including life satisfaction (a cognitive evaluation) and happiness (an affective evaluation) (Diener, 2006; Authors, 2017). In psychology, research on SWB was triggered by Brickman and Campbell (1971) who argued that most individuals had an equilibrium (set-point) level of SWB which was only temporarily disturbed by significant life events. The idea of a set-point dominated SWB research for nearly thirty years (Headey, 2007) but began to be undermined by evidence that certain events such as marriage (Gottman, 1996) or repeated unemployment (Clark et al., 2004) were associated with long-term changes in individuals' SWB. This led some (Headey, 2007) to argue that the study of 
SWB should concentrate on the factors leading to enduring changes in SWB such as having life goals linked to personal and social networks (e.g. family, friends, social participation). However, network research on subjective outcomes has remained comparatively uncommon (Hauberer, 2011; Authors, 2016a) and early influential social network research on SWB (Christakis and Fowler, 2009; Wilkinson, 2002; Helliwell, 2006) has also been convincingly criticised (Lyons, 2011). We attempt to address both the gap in the literature and some of these criticisms in this study.

The concept of social networks has been defined in various ways. It may refer to digital and online networks, personal relationships, political associations, economic transactions, and geopolitical relations among nations and international systems (Scott, 2017; Kadushin, 2012). In empirical studies social networks have been defined as formal and informal social relationships (Coleman, 1988; Authors 2017), properties of network structure (e.g. size and frequency of contact) (Huxhold et al., 2013), the norms (e.g. trust, reciprocity) that characterise networked relationships (Putnam, 2000) and positive outcomes from such relationships (e.g. economic output, social cohesion, health) (Helliwell and Putnam, 2004; Huxhold et al., 2013). As Durlauf and Fafchamps (2005) note, much research fails to clearly distinguish elements within bundles of related concepts (e.g. norms, trust, networks, positive outcomes), specify the mechanisms through which networks have effects, and develop rigorous measures and appropriate empirical analyses where network variables and theoretical assertions are tested alongside alternative explanations. In addition, prior research tended to assume that networks were only related to intended beneficial outcomes and did not consider adverse unintended consequences such as social exclusion or economic inefficiency (Coleman, 1988). Moreover, there was lack of scholarly attention to the dark side of social networks, such as relational and psychological stress, reduced SWB (Fox and Moreland, 2015; Kross et al., 2013) and negative relationships that impacted on workplace outcomes in organisations (Labianca and Brass, 2006). In the following sections, we offer a clear definition of social networks and propose a comprehensive and explicit model to examine both 'bright side' and 'dark side' effects of social networks on SWB. 


\section{Theoretical Model and Hypotheses}

In this study, a social network is broadly defined as a structure made up of a set of social actors or entities (such as individuals or organisations) and the relationships among them (Scott, 2017; Robins, 2015). The central research questions we want to address are: Are social networks associated with SWB? If so, what network characteristics or mechanisms are involved and to what effect? As mentioned above, the existing research of social networks on SWB has not been common but few welcoming exceptions have produced initial findings contributing to this field. Authors (2010) found SWB was significantly associated with social support people obtained from family members, friends, and acquaintances in Australia. In related studies of networks, trust and SWB, Authors (2005) showed that good neighbourly relations and wider social support networks significantly affect social trust; and Authors (2008) found that the social status of contacts, rather than the social distance between them, influenced social trust. More recently Authors (2016) showed that having good neighbourly relations and being actively engaged in civic activities was conducive to people's health, happiness and life satisfaction but network diversity moderated these relationships. Authors (2017) compared the relative importance of formal networks (e.g. group membership) and informal networks (e.g. contact with friends and family) in affecting people's SWB in Australia, Britain and China. The different research findings reflect the fact that research in this area uses different data sources and different analytical frameworks, rendering it difficult to establish a consensus about how and why social networks (e.g. types, facets and levels) influence SWB. We attempt to address this gap by proposing and examining a new model of social network influences on SWB. To do so, we firstly review classical accounts of social networks and then utilise the insights of the literature to develop our model and hypotheses.

Networks provide actors with resources to pursue desired outcomes. However, researchers disagree about why social networks matter (Lin, 2001). One key dispute is whether personal resources associated with network locations or embedded (i.e. social) resources associated with 
network connections matter. Within the network locations account, Bourdieu (1986) and Coleman (1988) hold that network positions lead to social benefits because they allow network members to recognise and mutually reward each other and exclude outsiders. Network location, in other words, allows group members to use social closure and group solidarity to pursue their interests.

Alternatively, Burt (1992) emphasises the importance of a strategic location or 'structural hole', such as a bridge linking networks, through which occupants gain advantages by accessing more diverse resources and influences or by controlling their access by other network members. Granovetter (1995) likewise stresses how an individual's weak ties (e.g. acquaintanceship) serve as information bridges between networks in job searches. These network mechanisms are linked to the positions or locations actors occupy and thus are individual positional attributes.

In contrast, in the embedded or social resources account (Lin, 2001) network resources are a meso-level property accessible through direct and indirect ties. Network resources may include things like the number of ties or the resources generated through ties. These resources are network, not actor, properties (Lin, 2001). Network locations facilitate access to better embedded resources but such resources are a property of the whole network, not an actor's position in it.

The foregoing discussion shows that the network location account calls attention to factors like network closure, density, and strategic position while the social resources account stresses resources that can be accessed or mobilised. However, no research has incorporated these elements in one comprehensive model using empirical data to test related assumptions. To address this gap we propose a new theoretical model incorporating network characteristics and network mechanisms (Figure 1). We include network mechanisms that may adversely affect SWB as well as those expected to enhance it.

Network characteristics include properties of network composition (e.g. size, density, and other features) and strength of ties between network members. These factors work with or through network mechanisms to influence SWB. The positive mechanisms associated with beneficial outcomes include social attachments, social resources and social support. Negative network 
mechanisms (i.e. mechanisms which we hypothesise as being associated with worse SWB) are relational constraints, which can be regarded as 'downward levelling norms' (Portes, 1998) or the 'dark side' of social networking experience (Fox and Moreland, 2015). Our theoretical model distils previous arguments (e.g. Granovetter, Lin, and Coleman) and posits separately measured network mechanisms to address conceptual and methodological criticisms that prior research does not specify or test (Durlauf and Fafchamps, 2005).

[Figure 1 about here]

Based on this model, we formulate the hypotheses below. The first two hypotheses focus on the association between network characteristics (i.e. network composition and strength of ties) and SWB reflecting arguments which emphasise network location (Bourdieu, 1986; Coleman, 1988; Burt, 1992; Granovetter, 1995). These hypotheses make explicit the positive associations between networks and SWB assumed in the literature (Durlauf and Fafchamps, 2005) and they supplement each other: Hypothesis 1 addresses density of networks (as a kind of network property), which indicates the closeness between and among all relevant network members. Hypothesis 2 stresses the strength of ties between the individual actor and his/her social contacts.

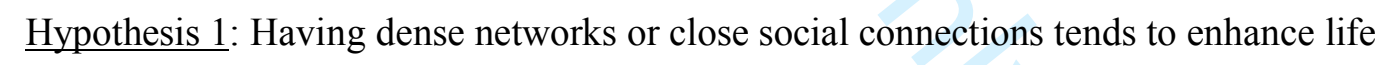
satisfaction and happiness.

Hypothesis 2: Having strong ties based on frequent contact and reciprocity tends to enhance life satisfaction and happiness.

Our other hypotheses investigate the associations between relational mechanisms and SWB (see Figure 1). In particular, Hypotheses 3-5 examine assertions about social attachment, social support and social resources respectively. Some of these factors have been examined in previous research (e.g. Lin, 2001; Van der Gaag and Snijders, 2005; Portela et al., 2013; Authors, 2016) but few studies have ever incorporated them in one model for empirical verification. 
Hypothesis 3: Having strong social attachments indicated by social participation, neighbourhood belonging and social trust tends to enhance life satisfaction and happiness.

Hypothesis 4: Having a higher level of perceived social support tends to enhance life satisfaction and happiness.

Hypothesis 5: Having more social resources tends to enhance life satisfaction and happiness.

Hypothesis 6 aims to investigate negative relational mechanisms that have been rarely studied in previous empirical research. We borrow ideas from Becker's (1991) rational choice theory and Honneth's (1996) account on social exclusion and social recognition and formulate the hypothesis below:

Hypothesis 6: Feeling stressed about social commitments, restricted by social demands, or excluded by social groups tends to decrease life satisfaction and happiness.

\section{Methods and Variables}

\section{Data}

We drew on data from the National Survey on Social Networks and Subjective Wellbeing in Australia (AuSNet 2014) for our statistical analysis (Authors, 2016b). AusNet 2014 is comprehensive personal network survey of the Australian adult population, based on a large national probability sample of adult respondents $(n=2,310)$. Our questionnaire is too varied in content and format to be administered by telephone interview and too expensive to be administered face-to-face by interviewers. We therefore opted for self-completion by respondents, either online or by mail. This is a cost-effective approach that allows respondents to see the questionnaire format.

We invited respondents into the study by telephone with numbers selected randomly 
using landline and mobile telephone sampling frames. Respondents had to be at least 18 years of age to be included. The landline recruitment sample was geographically stratified by state while the mobile recruitment was via a simple random sample, because Australian mobile phone numbers do not identify state of residence. Respondents who agreed to participate then completed questionnaires online or in hardcopy depending on their preference. The dual-frame (i.e. mobile and landline sampling frames) telephone recruitment strategy addresses population non-coverage issues associated with relying solely on a landline based sampling frame (Baffour et al., 2016). Respondents were first invited to complete the survey online, and if they declined were offered a hardcopy option through the mail. Offering our preferred survey mode first was more likely to lead to higher response rates than providing respondents with a choice of survey modes at the outset (Millar and Dillman, 2011). After follow-ups the final response rates for web and hardcopy completed surveys were $18.6 \%$ for recruitment from the landline sample, $26.9 \%$ for the mobile sample, and $22.7 \%$ for the overall sample (Authors, 2016c). The response rates are within ranges for web and mail surveys noted in a comprehensive meta-analysis of existing studies (Manfreda et al., 2008). For instance, an online survey investigating social capital and the use of social networking sites by college students had a lower response rate of $8.2 \%$ (Valenzuela et al., 2009).

\section{Dependent variables}

SWB is defined in terms of two key dimensions: a cognitive evaluation of one's life (life satisfaction) and an affective, emotional evaluation (happiness) (Diener, 2006; Davern et al., 2007). We measure these concepts as follows.

\section{Life satisfaction}

Life satisfaction is measured with the Satisfaction with Life Scale (Diener et al., 1985) which is among the most widely used measures in psychology and has been employed in a series of social surveys around the world (see Dolan et al. 2008 for a review). Respondents were asked to indicate their level of agreement about their life at present by giving a score (1-7, from 
"strongly disagree" to "strongly agree") to each of the following statements: 'In most ways my life is close to my ideal', 'The conditions of my life are excellent', 'I am satisfied with my life', 'So far I have gotten the important things I want in life', and 'If I could live my life over, I would change almost nothing' (Cronbach's $\alpha=.881$ ). As shown in Table 1, in the analytical sample of this paper, the average score of life satisfaction is 4.71 on a scale of 1-7.

\section{Happiness}

A scale of happiness was prepared for respondents for self-evaluation (Fordyce, 1977). Again this has been a classical measure in social science research. 'People often talk about "happiness" in their life. Where would you place yourself on a scale from 0 to 10 , where 0 means “extremely unhappy” and 10 means “extremely happy”?' The mean score of Australians' happiness is 8.07 on a scale of $1-11$, which is close to the results from previous surveys in Australia and Britain (Authors, 2017). There is also a positive correlation between life satisfaction and happiness $(\mathrm{r}=.723, \mathrm{p}<.01)$.

[Table 1 about here]

\section{Independent variables: network characteristics}

\section{Network composition}

We used Name generators (Burt, 1984) to measure network composition and asked respondents about their 'core discussion networks' (Marsden, 1987; McPherson et al., 2006), a type of strong-ties network that has been well documented in the literature. The questions were as follows: 'From time to time, most people discuss important matters with other people. Looking back over the last six months, have you discussed matters important to you with other people?' If so, 'with how many people have you discussed matters important to you?' Respondents were required to report their relationship with the named discussant (i.e. family or relative, including spouse/partner, friend, and other), how well they knew the named discussants and the mutual 
familiarity between the named discussants (i.e. on a 5-point scale, from “Don't know each other at all" to "Extremely familiar with each other"). Based on the information we construct four variables to indicate respondents' network composition, namely, the size of whole discussion network, the number of kin in the core discussion network, the number of non-kin in the core discussion network, and the density of core discussion network (see Table 1 ). ${ }^{1}$

\section{Strength of ties}

Granovetter $(1973,1995)$ suggested four dimensions measuring strength of ties: frequency of contact, emotional intensity, intimacy and reciprocal services. Authors (1997) added measures of role relationships such as kin, friends and acquaintances. In this study, the available information in the AuSNet questionnaire allowed us to construct two variables about the strength of ties among the members of the core discussion network: reciprocity of providing advice or help (strong=1) and frequency of contact (high=1), which are based on the following two questions: 'Did this person ask you for any advice or help in the last six months?' and 'Generally, how often do you contact each other?'. Strong reciprocity of helping means that at least $50 \%$ of the named discussants asked the respondent for advice or help. High frequency of contact indicates that the 'mean frequency of contact' (McPherson et al., 2006) among these discussion network members was at least once a week (i.e. 52 days per year).

\section{Independent variables: relational mechanisms}

\section{Social attachment}

Social attachment can be measured in terms of strength of connectedness across formal and informal relationships with others. We examine social attachment with variables measuring strength of formal organisational attachment, informal attachment, neighbourhood belonging and social trust:

(1) Club membership. Respondents were asked if they were currently an active member of a sporting, hobby or community-based club or association, and if it was the case, how many 
groups they were currently an active member of.

(2) Extent of social participation. Respondents were asked 'In general, how often do you get together socially with 'Family or relatives not living with you', 'Friends', 'Work colleagues', 'Neighbours', 'People at your place of worship', 'People at sporting activities or clubs', and 'People at service organisations (e.g. Rotary or Lions Club)'. The frequency ranges on a 6-point scale, from 'Less than once every 3 months' to 'Daily'. The sample average score of social participation is 2.19 on the scale of $1-6^{2}$.

(3) Neighbourhood belonging. Respondents were asked how strongly they agreed with the following three statements about their neighbourhood on a scale of 1-7, from "Strongly disagree" to "Strongly agree": 'You live in a close-knit neighbourhood', 'You have a sense of belonging to this neighbourhood' and 'People around here are willing to help their neighbours'. The average score of neighbourhood belonging is 4.65 on the 7-point scale.

(4) Social trust. Respondents were asked to what extent they agreed or disagreed with the following statements: 'Generally speaking, most people can be trusted', 'Generally speaking, you can't be too careful in dealing with people' and 'Generally speaking, most people would try to take advantage of you if they got a chance'. These questions are variants of the generalised trust scale well established in previous surveys in different countries. We reversed the scores of the last two statements when recoding and found that on a scale of 1-7 the average score was 3.94.

\section{Social support}

Social support refers to the kinds of assistance people can receive from others. We employed Resource Generators (Van der Gaag and Snijders, 2005) to identify different types of support people receive in their daily lives (Authors, 2015) by asking respondents if they had anyone to talk to for each type of support or problem out of 10 concrete scenarios when in need. Example scenarios included having problems with a partner or visiting someone for a chat. The average score is 8.75 out of 10 (see more details in Figure 2 in Appendices). 


\section{Social resources}

Social resources are resources generated through networks. We used Position Generators (Lin, 2001; Authors, 2000; Authors, 2008) to measure various aspects of network resources. Respondents were asked if they knew anyone who had any of the occupations from a list of 20 selected occupations (Table 2). We chose occupations which cover the spectrum of occupational status measured by the Australian Socioeconomic Index 2006 (AUSEI06) (McMillan et al., 2009). These occupational status measures proxy socioeconomic resources available through networks across the occupational status hierarchy.

[Table 2 about here]

We constructed four key variables: the number of occupations accessed, total status scores of occupations accessed, occupational ceiling (the highest occupational score), and occupational range (i.e. the difference between the highest and the lowest scores). These are measures of potential socioeconomic resources accessible to respondents through their networks (Authors, 2000; see Table 1). In particular, the first two variables measure the volume of network resources while the other two measure the diversity of network resources.

\section{Relational constraints and exclusion}

We created five dummy variables to measure relational constraints and exclusion (1=Yes): (1) Stress about social commitments. Respondents were asked 'Over the last three months, did you feel stressed about balancing your own needs against your social commitments (e.g. spending time with friends, taking care of family members, and joining activities of clubs)?' (2) Restriction of social demands. The question asked 'Over the last three months, do you feel your own freedom or ability to do what you want has been restricted by the demands of family or relatives, friends, acquaintances, or groups you are part of?' (3) Exclusion by social groups. Respondents were asked 'Have you ever felt excluded by a social group?' (4) Rules of club membership. Respondents were asked 'Does any social group you are associated with have rules 
for choosing members?' (5) Reluctance to provide help. Respondents were asked 'Have you ever been reluctant or unwilling to provide help when asked by family, relatives, friends or acquaintances?'.

\section{Control variables and method of analysis}

Our analyses include demographic and socioeconomic control variables for gender, age, educational level, employment status, household income, marital status, migration status, place of residence, religion, weekly hours spent on social activities, and weekly expenditure on social activities (see Table 1). These variables have been documented in previous studies on SWB (Dolan et al., 2008). To examine associations between social network variables and SWB we regress life satisfaction and happiness, respectively, on the network and control variables, using ordinary least squares linear regressions and then compute the average marginal effects (AME) to interpret model results. $^{3}$

Table 1 shows that our sample, like others, tends to underrepresent men and overrepresent the more highly educated. We can adjust for potential response bias associated with these variables by controlling them in our analyses. However, we cannot adjust for other potential source of bias that is unobserved, such as respondent sociability. If more sociable people are more likely to fill in questionnaires, and also more likely to be happier or more satisfied with their lives, not including sociability will bias our results. While this is a potential problem, we also expect sociability to be highly correlated with our network variables, and since we incorporate more diverse network variables in our analysis than other researchers, we potentially also better control any sociability response bias.

\section{Findings}

Table 3 shows the impact of network characteristics on SWB. All measures of network composition, namely, the size of whole discussion network, the number of kin and non-kin in core discussion networks and the density of core discussion networks are significantly associated with 
life satisfaction and happiness respectively. However, the two variables measuring strength of ties, namely, reciprocity of helping and frequency of contact among the members of the core discussion network are not significantly associated with SWB.

[Table 3 about here]

Table 4 extends the analysis by including the variables measuring relational mechanisms. This strategy helps achieve a greater understanding of the robustness of relationships between network variables and SWB as 'variables are systematically introduced into different models' (Dolan et al., 2008). Among network characteristics, the number of kin in the core discussion network is significantly associated with life satisfaction but not happiness, and density of the core discussion network is significantly associated with life satisfaction and happiness. These results lend strong support to Hypothesis 1 that having dense networks or close social connections among network members tends to enhance life satisfaction and happiness. By contrast, the two variables measuring strength of ties are not significantly associated with either life satisfaction or happiness, implying no real support for Hypothesis 2 .

\section{[Table 4 about here]}

We anticipated that social attachments, social support and social resources would be positively associated with SWB and relational constraints or exclusionary relationships would be negatively associated. Our findings are as follows: (1) Social attachment. Having club memberships and a strong sense of neighbourhood belonging are significantly associated with life satisfaction and happiness. This supports Hypothesis 3 that having strong social attachments tends to enhance life satisfaction and happiness. (2) Social support. Respondents with more types of perceived support are more satisfied and happier than respondents with fewer types of support. This lends support to Hypothesis 4 that having accessible social support tends to enhance life satisfaction and happiness. (3) Social resources. Other things being equal, we found only the total occupational status score of 
generated occupations is significantly associated with life satisfaction. The total score is a measure of the volume of socioeconomic resources available through networks (Authors, 2000). This dimension of these occupations refers to their hierarchical positioning on a socioeconomic status (SES) continuum. The volume measure indicates that the quantity of socioeconomic resources available through networks is associated with happiness and life satisfaction, but the diversity of resources, as indicated by the status range of networks, is not. This finding offers moderate support for Hypothesis 5. (4) Relational constraints. As predicted, stress about social commitments, restrictions from social demands, and exclusion by social groups are negatively associated with life satisfaction and happiness. Having been reluctant to provide help is negatively associated with life satisfaction as well. There is therefore significant support for hypothesis 6 . We summarise these results in Table 5.

\section{[Table 5 about here]}

Some demographic and socioeconomic factors are also significantly associated with SWB (Table 4). Women, high income earners, married and partnered individuals, those in paid employment, those spending more hours on social activities weekly, and rural residents are more satisfied with their lives and/or happier than men, those on lower incomes, single people, the unemployed and those not in the labour force, those spending less time on social activities, and urban residents, respectively. Older people are also less satisfied with their lives than younger people are.

\section{Summary and Discussion}

Drawing on the most recent and comprehensive national survey of Australians' social networks (AuSNet 2014) we contributed to understanding people's wellbeing in Australia empirically. Our results suggest that both network characteristics (i.e. features of networks associated with an 
individual's network location) and network mechanisms are associated with life satisfaction and happiness. These findings imply that SWB is not explained simply by sociostructural and economic factors (Diener 2006). Using different approaches and measures of network properties (e.g. name generators, position generators and resource generators) we have shown preliminary findings about the composition of individuals' core discussion networks, strength of social ties, social attachment, perceived social support, and social resources but also identified relational constraints and social exclusion. Overall, the analysis supports much of our proposed theoretical model, showing that network characteristics and positive and negative relational mechanisms are associated with Australians' life satisfaction and happiness. Moreover, the cognitive and affective evaluations of SWB, life satisfaction and happiness, are intertwined as social networks associations with them show similar patterns. In addition, the negative associations of social networks and SWB shed light on the study of 'dark side' of social networks (Fox and Moreland, 2015; Kross et al., 2013) and help explore the 'social ledger', namely, both the potential benefits and liabilities of social relationships (Labianca and Brass, 2006).

Not all of our expectations were supported. For instance, the strength of social ties among the core discussion network is not significantly associated with SWB and the association between social resources and SWB is only moderately supported. How can we make sense of these results? In other research, strong and weak ties (e.g. Granovetter, 1995, Authors, 1997; Authors, 2015) and access to social resources (Lin, 2001) have been found to matter for status attainment. However these network factors do not associate with SWB in our analysis. Lin (2001) differentiated two types of actions (i.e. instrumental and expressive actions) in his social resources theory. Following this classification we argue that enhancing SWB is an expressive action, which usually motivates an individual to 'seek out others with similar characteristics and lifestyles in order to share and confide...' Comparatively, an instrumental action 'motivates one to seek out others with dissimilar characteristics and lifestyles in order to access information and influence to achieve the expected return of more and/or better resources' (Lin, 2001: 59). Expressive actions tend to evoke 
homophilous interactions (i.e. interactions with those like ourselves) while instrumental actions are inclined to be associated with heterophilous interactions (interactions with those who differ from us). The varied socioeconomic network resources measured by position generators may be more closely related to heterophilous interactions and consequently to instrumental socioeconomic processes such as status attainment than to expressive processes such as maintaining and enhancing SWB. This may explain why the diversity of social resources is not significantly associated with SWB even though the volume of social resources is. Moreover, Authors' (2015) study revealed that weak ties are better able to channel information and strong ties are better able to mobilise forms of favouritism in job searches, which might imply that strong ties are more inclined to be involved in instrumental actions. Hence, strength of ties is probably not a significant factor associated with expressive outcomes such as SWB.

The next step in future study is to use longitudinal data where possible. Some existing longitudinal datasets incorporate some of the network variables in our analyses. In future work longitudinal data may offer some advantages for assessing causality, in cases where appropriate network variables are available. In addition, our model could also be extended by considering how it is shaped by macro-contextual factors. We consider two such factors particularly important, relational cultures and social structures. First, in some societies such as China and other East Asian countries, network relationships are tightly structured by cultural and normative expectations which emphasise interdependence and social connectedness over individualism and independence (Gold et al., 2002). In contrast, dominant cultures in Western countries (e.g. Australia and the UK) are more strongly individualistic. Strong, widespread relational understandings lead to shared expectations that linked actors will behave predictably in ways that reflect collective and relational expectations and obligations. In more individualistic societies, we might expect people to behave more on the basis of individual calculation and rationality. This argument suggests that our proposed relational mechanisms would exert greater impacts on people's SWB in a society like China than in Australia or the UK. Second, the rigidity of social boundaries is another factor that may moderate network 
effects. Where social boundaries are rigid, cross-boundary interactions are limited and structured. Where social boundaries are fluid, cross-boundary interactions are multifarious and varied. Australia has relatively high levels of social mobility and social barriers to the formation of friendship and marriage ties are comparatively weak (Authors, 1991), so social relationships are relatively heterogeneous, providing access to more diverse network resources. We might thus expect network effects on SWB to be enhanced in less rigid societies like Australia compared to other countries with more rigid social interaction and mobility. In future research we will pursue these two macro-level hypotheses about relational culture and the rigidity of social boundaries through focused comparative contrasts of our microlevel network theory in different countries such as Australia, China and the UK.

Finally, it should be recognised that that social networking sites (SNSs) play a growing role in individuals' social networks, especially for younger people. We have not considered online social networks in this paper but they offer opportunities to test our model in online as well as face-to-face networks. Previous studies of the impact of online social networks on individuals' SWB have produced mixed results, paralleling the situation with face-to-face network research. Most research focuses on the use of Facebook, the most popular SNS globally. Some scholars suggested that there were positive associations between intensity of Facebook use and college students' life satisfaction, social trust, and civic engagement (Valenzuela et al., 2009). Facebook usage interacted with psychological wellbeing and offered greater benefits for users experiencing low self-esteem and low life satisfaction (Ellison et al., 2007). The number of Facebook friends and self-presentation strategies were found to help enhance SWB by different paths (Kim and Lee, 2011). On the other hand, it was revealed that Facebook use predicted negative effect on young adults' SWB (Kross et al., 2013). Even though Facebook users often experienced negative emotions and psychological stress, they felt pressured to access the site frequently to keep up with relationship maintenance demands (Fox and Moreland, 2015). Our future work will attempt to collect relevant data and investigate the mechanism through which online social networks (not only about Facebook) 
influence SWB, positively and negatively, and to compare the roles of online versus offline social capital. This can be a promising direction of inquiry in the field of social networks and SWB.

\section{Notes:}

1. Density is 'operationalized using dichotomous data on tie strength as the proportion of possible ties among alters actually present' (Marsden, 1987). More details about the measures of discussion network are available in Appendices (Table 1a and Table 1b).

2. In the questionnaire we had a range of questions that were used to construct scales. Response options for these items varied, from 5-point to 7-point for example. The main reason for this was that we replicated or adapted some questions from previous national or international surveys for comparative analysis.

3. The AME models are based on OLS regressions. The eydx option of the margins command in STATA allowed us to turn the coefficients into elasticities, which mean proportional changes in the dependent variable for unit changes in independent variables. The coefficients from the AME models can thus be understood as percentage-point differences with reference categories for categorical variables, or as percentage-point changes for unit changes in continuous variables.

\section{References:}

Baffour B, Haynes M, Western M, Pennay D, Mission S and Martinez A (2016) Weighting strategies for combining data from dual-frame telephone surveys: Emerging evidence from Australia. Journal of Official Statistics 32(3): 549-578.

Becker GS (1991) A Treatise on the Family. Cambridge, Massachusetts: Harvard University Press.

Bourdieu P (1986) The forms of capital. In: Richardson J (ed.) Handbook of Theory and Research for the Sociology of Education. New York: Greenwood, 241-258.

Brickman PD and Campbell DT (1971) Hedonic relativism and planning the good society. In: Appley MH (ed.) Adaptation Level Theory. New York: Academic Press.

Burt R (1984) Network items and the General Social Survey. Social Networks 6: 293-339.

Burt R (1992) Structural Holes: The Social Structure of Competition. Cambridge, Massachusetts: Harvard University Press.

Christakis N and Fowler J (2009) Connected: The Surprising Power of Our Social Networks and How They Shape Our Lives. New York: Little, Brown and Company.

Clark, AE, Georgellis Y, Lucas RE and Diener E (2004) Unemployment alters the set point for life satisfaction. Psychological Science 15: 8-13.

Coleman, JS (1988) Social capital in the creation of human capital. American Journal of Sociology 
94: $95-120$.

Davern M, Cummins R and Stokes M (2007) Subjective wellbeing as an affective-cognitive construct. Journal of Happiness Studies 8:429-449.

Diener, E (2006) Guidelines for national indicators of subjective well-being and ill-being, Journal of Happiness Studies 7:397-404.

Diener E, Emmons RA, Larsen RJ and Griffin S (1985) The satisfaction with life scale. Journal of Personality Assessment 49: 71-75.

Dolan P, Peasgood T and White M (2008) Do we really know what makes us happy? A review of the economic literature on the factors associated with subjective well-being. Journal of Economic Psychology 29:94-122.

Durlauf S and Fafchamps M (2005) Social Capital. In: Aghion P and Durlauf S (ed.) Handbook of Economic Growth, vol.1. Elsevier, 1639-1699.

Ellison N, Steinfield C and Lampe C (2007) The benefits of Facebook "friends": Social capital and college students' use of online social network sites. Journal of Computer-Mediated Communication 12: 1143-1168.

Fordyce M (1977) Development of a program to increase personal happiness, Journal of Counselling Psychology 24: 511-520.

Fox J and Moreland J (2015) The dark side of social networking sites: An exploration of the relational and psychological stressors associated with Facebook use and affordances. Computers in Human Behavior 45: 168-176.

Furstenberg F and Hughes M (1995) Social capital and successful development among at-risk youth. Journal of Marriage and the Family 57: 580-592.

Gold T, Guthrie D and Wank D (2002) Social Connections in China: Institutions, Culture, and the Changing Nature of Guanxi. Cambridge University Press.

Gottman, JM (1996) What Predicts Divorce? The Relationship between Marital Processes and Marital Outcomes. Hillsdale, N.J.: Lawrence Erlbaum.

Granovetter M (1973) The strength of weak ties. American Journal of Sociology 78: 1360-1380.

Granovetter M (1995) Afterword 1994: Reconsiderations and a new agenda. In: Getting a Job. The University of Chicago Press, 139-182.

Hagan J, MacMillan R and Wheaton B (1996) New kid in town: Social capital and the life course effects of family migration on children. American Sociological Review 61: 368-385.

Hagan J and McCarthy B (1995) Getting into street crime: The structure and process of criminal embeddedness. Social Science Research 24: 63-95.

Hauberer, J (2011) Social Capital Theory: Towards a Methodological Foundation. Springer Fachmedien Wiesbaden GmbH. 
Headey B (2007) The Set-point Theory of Wellbeing Needs Replacing - On the Brink of a Scientific Revolution? Discussion Paper 753. German Institute for Economic Research. Berlin.

Helliwell, JF (2006) Wellbeing, social capital and public policy: What's new?', Economic Journal 116(510): C34-C45.

Helliwell JF and Putnam R (2004) The social context of well-being, Philosophical Transactions of the Royal Society 359(1449): 1435-1446.

Honneth A (1996) The Struggle for Recognition: The Moral Grammar of Social Conflicts, MIT Press.

Huxhold O, Fiori K and Windsor T (2013) The dynamic interplay of social network characteristics, subjective well-being, and health: The costs and benefits of socio-emotional selectivity. Psychology and Aging 28(1): 3-16.

Kadushin C (2012) Understanding Social Networks: Theories, Concepts, and Findings, Oxford University Press.

Kim J and Lee J (2011) The Facebook paths to happiness: Effects of the number of Facebook friends and self-presentation on subjective well-being. Cyberpsychology, Behavior, and Social Networking 14(6): 359-364.

Kross E, Verduyn P, Demiralp E, Park J, Lee DS, Lin N, Shablack1 H, Jonides1 J and Ybarra O (2013) Facebook use predicts declines in subjective well-being in young adults. PLoS ONE 8(8): e69841. doi:10.1371/journal.pone.0069841

Labianca G and Brass D (2006) Exploring the social ledger: Negative relationships and negative asymmetry in social networks in organizations. The Academy of Management Review 31(3): 596614.

Lin N (2001) Social Capital: A Theory of Social Structure and Action. Cambridge University Press.

Lyons R (2011) The spread of evidence-poor medicine via flawed social-network analysis.

Statistics, Politics, and Policy 2(1): Article 2.

Manfreda KL, Bosnjak M, Berzelak J, Haas I and Vehovar V (2008) Web surveys versus other survey modes: A meta-analysis comparing response rates. International Journal of Market Research 50: 79-104.

Marsden P (1987) Core discussion networks of Americans. American Sociological Review 52:122131.

McMillan J, Beavis A and Jones F (2009) The AUSEI06: A new socioeconomic index for Australia. Journal of Sociology 45:123-149.

McPherson M, Smith-Lovin L and Brashears ME (2006) Social isolation in America: Changes in core discussion networks over two decades. American Sociological Review 71: 353-375.

Millar M and Dillman DA (2011) Improving response to web and mixed-mode surveys. Public Opinion Quarterly 75: 249-269. 
Portela M, Neira I and Salinas-Jimenez M (2013) Social capital and subjective wellbeing in Europe: A new approach on social capital. Social Indicators Research 114:493-511.

Portes A (1998) Social capital: Its origins and applications in modern sociology. Annual Review of Sociology 24: 1-24.

Putnam R (2000) Bowling Alone. New York: Simon \& Schuster.

Robins G (2015) Doing Social Network Research: Network-based Research Design for Social Scientists, Sage.

Scott J (2017) Social Network Analysis. Sage.

Valenzuela S, Park N and Kee K (2009) Is there social capital in a social network site?: Facebook use and college students' life satisfaction, trust, and participation. Journal of Computer-Mediated Communication 14:875-901.

Van der Gaag M and Snijders T (2005) The resource generator: Social capital quantification with concrete items. Social Networks 27: 1-29.

Wilkinson R (2002) Liberty, fraternity, equality. International Journal of Epidemiology 31: 538543. 
Table 1. Descriptive Statistics of Variables, AuSNet Survey, 2014 (N=1713)

\begin{tabular}{|c|c|}
\hline Variables & Mean (S.D.) or \% \\
\hline \multicolumn{2}{|l|}{ Subjective wellbeing (SWB) } \\
\hline Life satisfaction (on a scale of 1-7) & $4.71(1.35)$ \\
\hline Happiness (on a scale of 1-11) & $8.07(1.79)(\mathrm{N}=1708)$ \\
\hline \multicolumn{2}{|l|}{ Network composition } \\
\hline Size of whole discussion network & $5.97(12.55)$ \\
\hline Number of kin in core discussion network & $1.65(1.27)$ \\
\hline Number of non-kin in core discussion network & $2.08(1.36)$ \\
\hline Density of core discussion network $(0-1)$ & $.67(.20)$ \\
\hline \multicolumn{2}{|l|}{ Strength of ties } \\
\hline \%Reciprocity of providing advice/help (strong=1) & 83.65 \\
\hline$\%$ Frequency of contact (high=1) & 79.80 \\
\hline \multicolumn{2}{|l|}{ Social attachment } \\
\hline \%Having one club membership & 22.42 \\
\hline$\%$ Having more than one club membership & 28.20 \\
\hline Extent of social participation (on a scale of 1-6) & $2.19(.81)$ \\
\hline Neighbourhood belonging (on a scale of 1-7) & $4.65(1.35)$ \\
\hline Social trust (on a scale of 1-7) & $3.94(.81)$ \\
\hline \multicolumn{2}{|l|}{ Social support } \\
\hline Types of perceived support $(0-10)$ & $8.75(1.73)$ \\
\hline \multicolumn{2}{|l|}{ Social resources } \\
\hline Number of contacts in listed occupations $(0-20)$ & $9.58(4.56)$ \\
\hline Total status score of generated occupations & $583.35(278.54)$ \\
\hline Highest status score of generated occupations & $93.02(11.39)$ \\
\hline Range of status scores of generated occupations & $68.58(19.56)$ \\
\hline \multicolumn{2}{|l|}{ Relational constraints and exclusion } \\
\hline$\%$ Stress about social commitments & 72.50 \\
\hline \%Restriction of social demands & 70.11 \\
\hline$\%$ Exclusion of social groups & 39.23 \\
\hline \%Rules of club membership & 18.80 \\
\hline$\%$ Reluctance of providing help & 69.12 \\
\hline \multicolumn{2}{|l|}{ Demographic \& socioeconomic characteristics } \\
\hline$\%$ Gender $($ male $=1)$ & 41.21 \\
\hline Age & $48.13(16.01)$ \\
\hline $\mathrm{Age}^{2} / 100$ & $2572.92(1585.05)$ \\
\hline$\%$ Certificate or diploma & 31.29 \\
\hline$\%$ Bachelor degree and above & 44.60 \\
\hline$\%$ Other education qualification (ref.) & 24.11 \\
\hline$\%$ Employee or self-employed (ref.) & 59.02 \\
\hline$\%$ Unemployed or looking for work & 3.21 \\
\hline$\%$ Retired & 13.31 \\
\hline$\%$ Full-time student & 5.49 \\
\hline$\%$ Household duties & 7.76 \\
\hline$\%$ Other employment status & 11.21 \\
\hline \%Low household income (\$799 per week and below) & 17.40 \\
\hline \%Middle income ( $\$ 800$ - $\$ 1,499$ per week) & 20.14 \\
\hline$\%$ High income ( $\$ 1,500$ per week and above) (ref.) & 47.93 \\
\hline$\%$ Single/never married (ref.) & 19.61 \\
\hline$\%$ Married or de facto & 65.38 \\
\hline \%Divorced or separated & 11.56 \\
\hline$\%$ Widowed & 3.44 \\
\hline$\%$ Migrant & 26.21 \\
\hline$\%$ Urban resident & 64.80 \\
\hline$\%$ Having a religion & 53.01 \\
\hline Weekly hours on social activities & $10.64(11.86)$ \\
\hline \$Weekly expenditure on social activities & $79.03(81.93)$ \\
\hline
\end{tabular}

Note: The results in this table are based on variables that are included in the full models in Table 4. 
1

2

3

4

5

6

7

8

9

10

11

12

13

14

15

16

17

18

19

20

21

22

23

24

25

26

27

28

29

30

31

32

33

34

35

36

37

38

39

40

41

42

43

44

45

46

47

48

49

50

51

52

53

54

55

56

57

58

59

60

Table 2. Listed Occupations and Status Scores

\begin{tabular}{lc}
\hline Occupation & AUSEI06 \\
\hline General Practitioner & 100.00 \\
University lecturer & 92.30 \\
Solicitor/Barrister & 90.70 \\
Engineer & 86.10 \\
Primary/Secondary School Teacher & 86.10 \\
Accountant & 83.70 \\
Finance Manager & 81.50 \\
Nurse & 80.70 \\
Journalist & 77.40 \\
Police Officer & 64.00 \\
Secretary & 44.80 \\
Clerk in Public Service & 54.30 \\
Electrician & 39.60 \\
Waiter/Waitress & 36.50 \\
Farmer & 34.00 \\
Shop/Sales Assistant & 30.80 \\
Bus/Coach Driver & 29.90 \\
Chef & 26.60 \\
Cleaner & 20.40 \\
Factory Worker & 12.10 \\
\hline
\end{tabular}


Table 3. Average marginal effects of network characteristics on SWB, AuSNet survey, 2014

\begin{tabular}{lll}
\hline Independent variables & Life satisfaction & Happiness \\
\hline Network composition & & \\
$\quad$ Size of whole discussion network & $.001 !$ & $.001 !$ \\
Number of kin in core discussion network & $.026^{* * *}$ & $.009 !$ \\
Number of non-kin in core discussion network & $.024^{* * *}$ & $.016^{* *}$ \\
Density of core discussion network & $.221^{* * *}$ & $.209^{* * *}$ \\
Strength of ties & & \\
$\quad$ Reciprocity of helping (strong =1) & .004 & -.002 \\
Frequency of contact (high=1) & .017 & .017 \\
Control variables $^{a}$ & & .120 \\
$R^{2}$ & .144 & 1805 \\
Number of cases & 1813 & \\
\hline
\end{tabular}

Note: Two detailed test: $! \mathrm{p}<.10,{ }^{*} \mathrm{p}<.05,{ }^{* *} \mathrm{p}<.01,{ }^{*} * \mathrm{p}<.001$

${ }^{\text {a }}$ Control variables are included but not presented here due to space constraints. Models with full details are presented in Table 4 . The results related to control variables are very similar in both tables. 
Table 4. Average marginal effects of network characteristics and relational mechanisms on SWB, AuSNet survey, 2014

\begin{tabular}{|c|c|c|}
\hline Independent variables & Life satisfaction & Happiness \\
\hline \multicolumn{3}{|l|}{ Network composition } \\
\hline Size of whole discussion network & .001 & .001 \\
\hline Number of kin in core discussion network & $.018 * *$ & .005 \\
\hline Number of non-kin in core discussion network & .010 & .006 \\
\hline Density of core discussion network & $.130 * *$ & $.130 * * *$ \\
\hline \multicolumn{3}{|l|}{ Strength of ties } \\
\hline Reciprocity of helping (strong=1) & .001 & -.004 \\
\hline Frequency of contact (high=1) & .010 & .005 \\
\hline \multicolumn{3}{|l|}{ Social attachment } \\
\hline Having one club membership & .020 & $.024 !$ \\
\hline Having more than one club membership & $.035^{*}$ & $.025 !$ \\
\hline Extent of social participation & .010 & $.012 !$ \\
\hline Neighbourhood belonging & $.039 * * *$ & $.027 * * *$ \\
\hline Social trust & -.004 & -.010 \\
\hline \multicolumn{3}{|l|}{ Social support } \\
\hline Types of perceived support & $.008 !$ & $.005 !$ \\
\hline \multicolumn{3}{|l|}{ Social resources } \\
\hline Number of contacts in listed occupations & -.012 & $-.010 !$ \\
\hline Total status score of generated occupations & $.000 *$ & $.000 *$ \\
\hline Highest status score of generated occupations & -.001 & -.010 \\
\hline Range of status scores of generated occupations & .000 & .000 \\
\hline \multicolumn{3}{|l|}{ Relational constraints and exclusion } \\
\hline Stress about social commitments & $-.070 * * *$ & $-.041 * *$ \\
\hline Restriction of social demands & $-.042 * *$ & $-.047 * * *$ \\
\hline Exclusion of social groups & $-.071 * * *$ & $-.060 * * *$ \\
\hline Rules of club membership & -.014 & -.005 \\
\hline Reluctance of providing help & $-.033 *$ & -.015 \\
\hline \multicolumn{3}{|l|}{ Control variables } \\
\hline Gender $($ male $=1)$ & $-.038 * *$ & -.008 \\
\hline Age & $-.010 * * *$ & $-.005 *$ \\
\hline $\mathrm{Age}^{2}$ & $.000 * * *$ & $.000^{*}$ \\
\hline \multicolumn{3}{|l|}{ Education (ref.= other education qualification) } \\
\hline Certificate or diploma & -.016 & -.014 \\
\hline Bachelor degree and above & .016 & .012 \\
\hline \multicolumn{3}{|l|}{ Employment status (ref.= employee or self-employed) } \\
\hline Unemployed or looking for work & $-.111 * *$ & $-.106 * *$ \\
\hline Retired & .035 & .013 \\
\hline Full-time student & .020 & .005 \\
\hline Household duties & -.013 & -.010 \\
\hline Other employment status & $-.046^{*}$ & -.019 \\
\hline \multicolumn{3}{|l|}{ Household income (ref. $=$ high income) } \\
\hline Low income & $-.066 * *$ & $-.039 *$ \\
\hline Middle income & -.023 & -.003 \\
\hline \multicolumn{3}{|l|}{ Marital status (ref. $=$ single/never married) } \\
\hline Married or de facto & $.093 * * *$ & $.084 * * *$ \\
\hline Divorced or separated & -.024 & .017 \\
\hline Widowed & .059 & .052 \\
\hline Migrant & -.010 & -.000 \\
\hline Urban resident & $-.030 *$ & $-.021 !$ \\
\hline Having a religion & .016 & .014 \\
\hline Weekly hours on social activities & $.002 * *$ & $.001 * *$ \\
\hline Weekly expenditure on social activities & .000 & .000 \\
\hline$R^{2}$ & .250 & .221 \\
\hline Number of cases & 1713 & 1708 \\
\hline
\end{tabular}

Note: Two detailed test: $\mathrm{p}<.10,{ }^{*} \mathrm{p}<.05,{ }^{*} \mathrm{p}<.01,{ }^{*} * \mathrm{p}<.001$ 
Sociology Paper For Review

Page 26 of 30

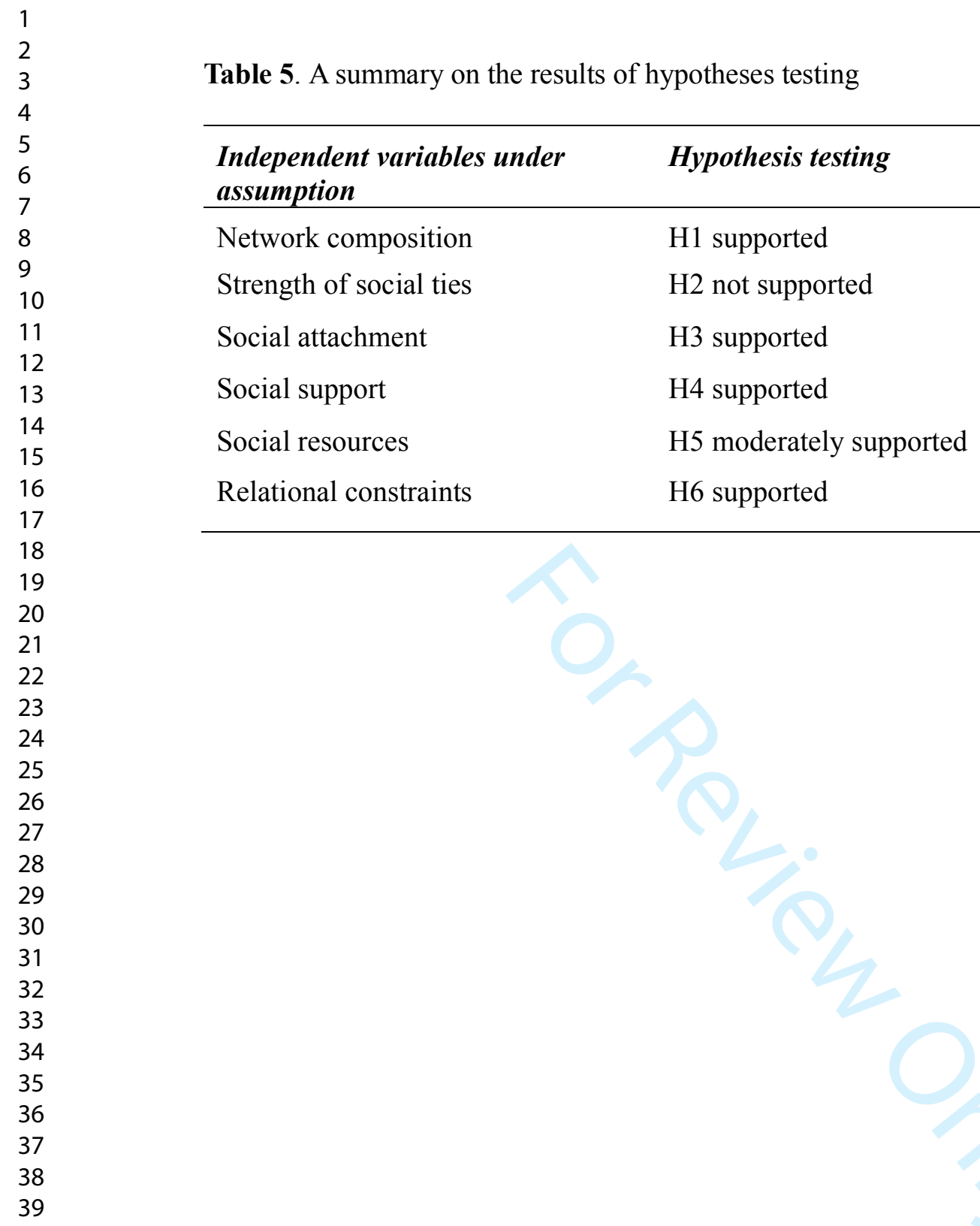

3

4

5

6

Independent variables under assumption

8

9

10

11

12

13

14

15

16

17

18

19

20

21

22

23

24

25

26

27

28

29

30

31

32

33

34

35

36

37

38

39

Network composition

Strength of social ties

Social attachment

Social support

Social resources

Relational constraints

Hypothesis testing

H1 supported

H2 not supported

H3 supported

H4 supported

H5 moderately supported

H6 supported

40

41

42

43

44

45

46

47

48

49

50

51

52

53

54

55

56

57

58

59

60

26 
Figure 1 Theoretical model of network characteristics and mechanisms on SWB

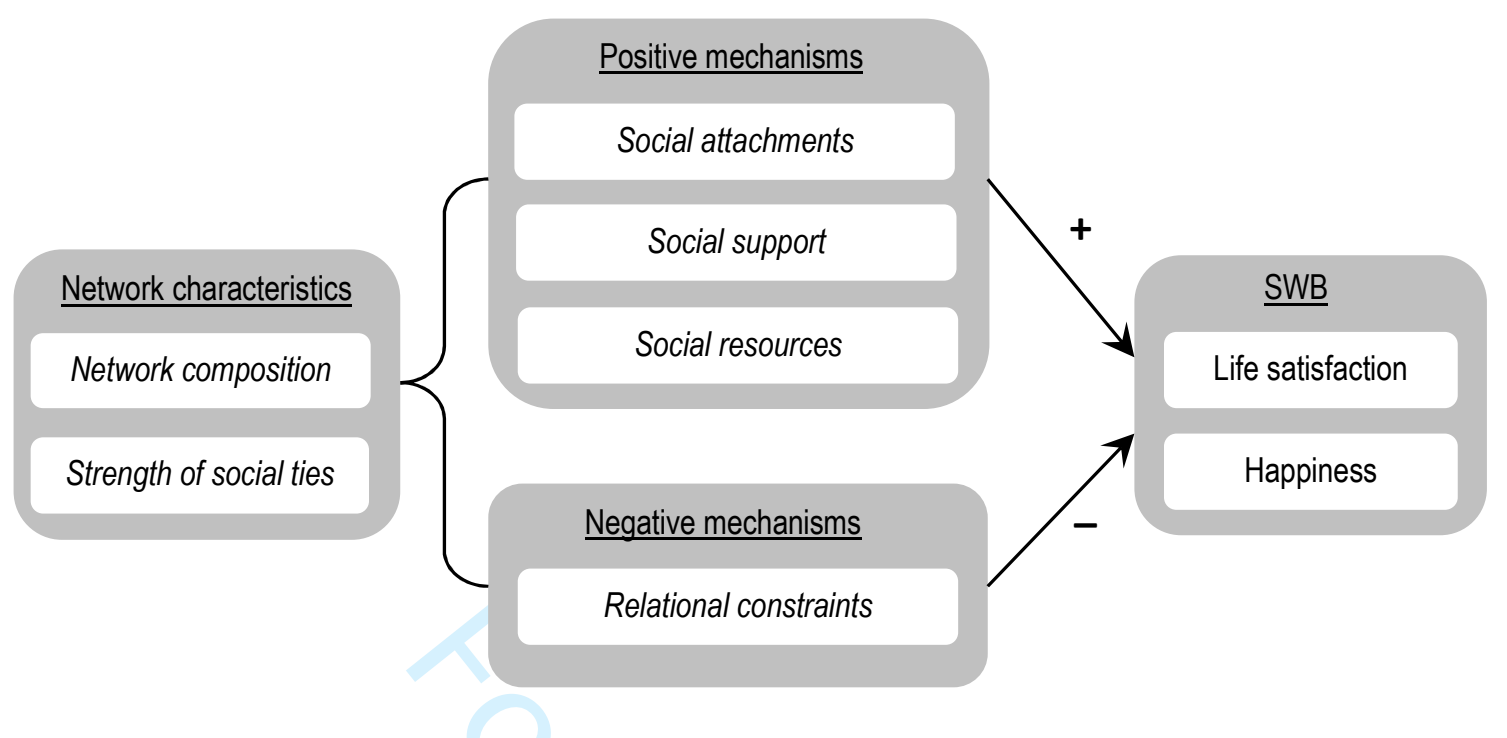

Note: This model is informed by literature review and constructed by using authors' knowledge and insights. 


\section{Appendices:}

Table 1a. Univariate distribution of measures of discussion network, AuSNet survey, 2014

\begin{tabular}{|c|c|c|c|c|c|}
\hline+2 & Value & $\%$ & Mean & $\begin{array}{l}\text { Standard } \\
\text { Deviation }\end{array}$ & $(\mathrm{N})$ \\
\hline Overall network size & $\begin{array}{l}0 \\
1 \\
2 \\
3 \\
4 \\
5 \\
6+\end{array}$ & $\begin{array}{l}16.5 \\
5.3 \\
13.0 \\
14.9 \\
12.3 \\
12.7 \\
25.3\end{array}$ & 4.88 & 11.11 & 2294 \\
\hline Kin network size & $\begin{array}{l}0 \\
1 \\
2 \\
3 \\
4 \\
5\end{array}$ & $\begin{array}{l}34.9 \\
23.9 \\
20.6 \\
13.3 \\
5.5 \\
1.9 \\
\end{array}$ & 1.36 & 1.32 & 2310 \\
\hline Nonkin network size & $\begin{array}{l}0 \\
1 \\
2 \\
3 \\
4 \\
5\end{array}$ & $\begin{array}{l}27.9 \\
19.6 \\
22.9 \\
16.0 \\
9.3 \\
4.4\end{array}$ & 1.72 & 1.47 & 2310 \\
\hline Proportion kin & $\begin{array}{l}0.00 \\
0.01-0.33 \\
0.34-0.66 \\
0.67-0.99 \\
1.00\end{array}$ & $\begin{array}{l}21.5 \\
17.9 \\
34.3 \\
13.3 \\
13.0\end{array}$ & .44 & .32 & 1914 \\
\hline Density & $\begin{array}{l}<.25 \\
0.25-0.49 \\
0.50-0.74 \\
>0.74\end{array}$ & \begin{tabular}{l|}
0.8 \\
14.5 \\
49.3 \\
35.4 \\
\end{tabular} & .67 & .20 & 1845 \\
\hline $\begin{array}{l}\text { Age heterogeneity } \\
\text { Std. deviation }\end{array}$ & $\begin{array}{l}<5 \\
5-<10 \\
10-<15 \\
15+ \\
\end{array}$ & $\begin{array}{l}19.5 \\
31.7 \\
27.0 \\
21.8\end{array}$ & 9.59 & 6.03 & 1773 \\
\hline $\begin{array}{l}\text { Education heterogeneity } \\
\text { Std. deviation }\end{array}$ & $\begin{array}{l}0-1 \\
>1-2.5 \\
>2.5\end{array}$ & $\begin{array}{l}28.1 \\
49.5 \\
22.4\end{array}$ & 1.69 & 1.16 & 1695 \\
\hline Gender heterogeneity (IQV) & $\begin{array}{l}0 \\
0.01-0.90 \\
>0.90\end{array}$ & $\begin{array}{l}30.3 \\
37.2 \\
32.5\end{array}$ & .59 & .41 & 1914 \\
\hline Employment status heterogeneity (IQV) & $\begin{array}{l}0 \\
0.01-0.60 \\
>0.60\end{array}$ & $\begin{array}{l}27.6 \\
44.3 \\
28.1 \\
\end{array}$ & .44 & .30 & 1916 \\
\hline Job position heterogeneity (IQV) & $\begin{array}{l}0 \\
0.01-0.60 \\
>0.60\end{array}$ & $\begin{array}{l}30.6 \\
29.9 \\
39.5\end{array}$ & .44 & .32 & 1907 \\
\hline Purpose of discussion (IQV) & $\begin{array}{l}0 \\
0.01-0.75 \\
>0.75\end{array}$ & $\begin{array}{l}43.5 \\
45.0 \\
11.5\end{array}$ & .40 & .37 & 1900 \\
\hline Mean frequency of contact (days per year) & $\begin{array}{l}<12 \\
12-52 \\
53-183 \\
184-365\end{array}$ & $\begin{array}{l}3.4 \\
27.3 \\
41.9 \\
27.4\end{array}$ & 138.77 & 101.08 & 1919 \\
\hline
\end{tabular}


Table 1b. Size of discussion networks: comparison

\begin{tabular}{lrrr}
\hline Network size & \multicolumn{3}{c}{ Total discussion network (\%) } \\
\cline { 2 - 4 } & AuSNet2014 & LIQ2008 & GSS 2004 \\
\hline 0 & 16.5 & 20.3 & 24.6 \\
1 & 5.3 & 5.2 & 19.0 \\
2 & 13.0 & 10.7 & 19.2 \\
3 & 14.9 & 12.4 & 16.9 \\
4 & 12.3 & 11.1 & 8.8 \\
5 & 12.7 & 15.2 & 6.5 \\
$6+$ & 25.3 & 25.1 & 4.9 \\
& & & \\
Mean & 4.88 & 4.86 & 2.08 \\
SD & 11.11 & 7.14 & 2.05 \\
N & 2294 & 3958 & 1467 \\
\hline & & Kin network (\%) & \\
Network size & LIQ2008 & GSS 2004 \\
\hline 0 & 34.9 & 30.0 & 39.6 \\
1 & 23.9 & 17.1 & 29.7 \\
2 & 20.6 & 19.3 & 16.0 \\
3 & 13.3 & 17.8 & 9.4 \\
4 & 5.5 & 10.4 & 4.0 \\
5 & 1.9 & 5.4 & 1.3 \\
& & & \\
Mean & 1.36 & 1.77 & 1.12 \\
SD & 1.32 & 1.55 & 1.38 \\
N & 2310 & 3959 & 1467 \\
\hline
\end{tabular}

Source: AuSNet Survey 2014 and our previous research findings (Authors, 2015) 
Figure 2. Type of perceived social support by sources, AuSNet survey, 2014 ( $\mathrm{N}=2310)$
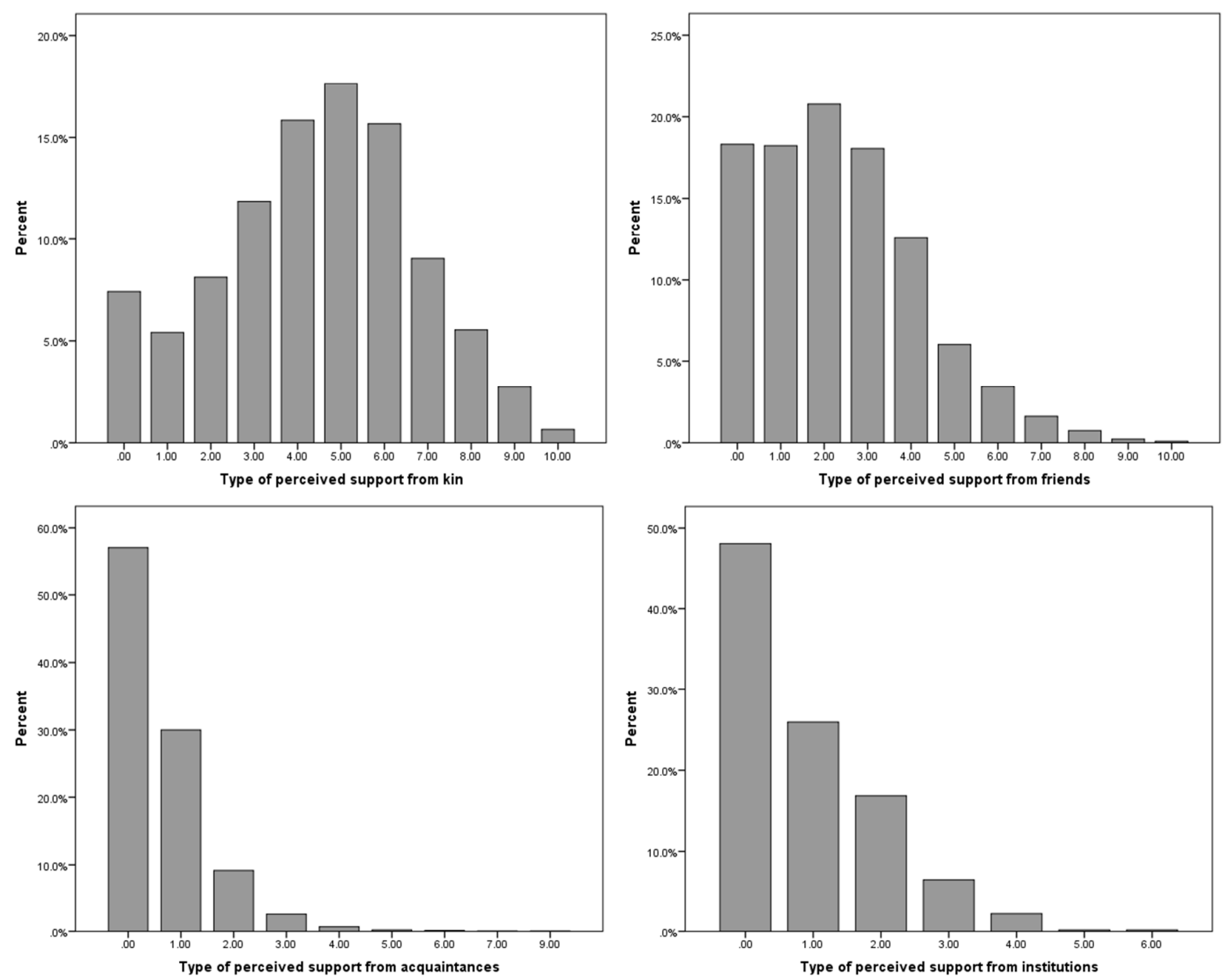